DOI: 10.12731/2227-930X-2019-4-11-14 УДК 373.62

\title{
МЕТОДОЛОГИЯ ИСПОЛЬЗОВАНИЯ ИНТЕЛЛЕКТУАЛЬНЫХ КОМПЬЮТЕРНЫХ ИГР В ОБУЧЕНИИ ИНФОРМАЦИОННЫМ ТЕХНОЛОГИЯМ
}

\begin{abstract}
Гибадуллин А.А.
Данная статья посвящена комплексу методических разработок, которые позволяют проводить обучение информационным технологиям при помощчи соответствующих интеллектуальных игр. Автор отмечает их положительный эффект. Он заключается в том, что они способствуют развитию обучающихся, стимулируют их мотивацию. Характерной особенностью является отсутствие эффекта привыкания и потери чувства реальности. При этом интеллектуальная компонента находится на первом месте и становится определяющей.

Ключевые слова: компьютерное обучение; игровое обучение; игровой интеллект; машинная педагогика; информатизация; образовательный прочесс.

\section{METHODOLOGY OF USING \\ INTELLECTUAL COMPUTER GAMES IN TEACHING INFORMATION TECHNOLOGIES}

\section{Gibadullin A.A.}

This article is devoted to a set of methodological developments that allow training in information technology using appropriate intellectual games. The author notes their positive effect. It lies in the fact that they contribute to the development of students, stimulate their motivation. A characteristic feature is the lack of addiction and loss of a sense of reality. At the same time, the intellectual component is in the first place and becomes decisive.
\end{abstract}


Keywords: computer training; game training; game intelligence; machine pedagogy; informatization; educational process.

Компьютерные игры занимают важное место среди информационных технологий. С одной стороны, они являются результатом их развития. Ведь обычно для разработки используется самое современное программное и аппаратное обеспечение. С другой стороны, они способствуют их популяризации. Даже человек далекий от программирования, так или иначе, был потребителем продуктов игровой компьютерной индустрии. Это, в свою очередь, способствует росту интереса к IT-сфере у населения.

Компьютерные игровые технологии многогранны и охватывают различные области: виртуальную реальность, интернет, сферы программного и аппаратного обеспечения. К тому же они служат индикатором информационного прогресса человечества. Это связано с тем, что они отражают технологический и программный уровень развития в IT-сфере.

Особое место среди них занимают интеллектуальные компьютерные игры. Ведь помимо их развлекательной составляющей, они по своей сути являются разновидностью умственных соревнований между людьми и техникой. Это делает возможным рассматривать их в контексте искусственного интеллекта, а также человеко-компьютерного взаимодействия и применения соответствующих алгоритмов и эвристик [1].

Еще один важный момент заключается в том, что в отличие от большинства интерактивных развлечений, которые многие критикуют и обвиняют в негативном влиянии на психику и развитие человека, подмену реального мира на виртуальный, интеллектуальные соревнования имеют развивающий и обучающий характер. Следовательно, они лишены указанных недостатков.

Наиболее популярным и распространенным методом реализации поведения является технология нейронных сетей [2]. Дело в том, что их не программируют, а обучают определенным образом. Это позволяет провести параллели между обучением человека и 
машины. В век стремительно развивающихся технологий данный процесс становится все более актуальным.

В своем исследовании автор создает интерактивную систему, по одну сторону которой обучение человека, по другую обучение машины. Интеллектуальной компьютерной игре отводится роль посредника между этими двумя компонентами. Дело в том, что формирование сознания происходит на основе сюжетных линий. У нас доминирует ситуационно-образное мышление. Для людей древности это соответствовало мифологическому или легендарному мышлению. В ходе развития личности, равно как и в биологическом процессе эволюции восприятия, примитивные реакции объединяются в сюжеты, а затем и в целые миры. Важной особенностью компьютерных игр является то, что они формируют сюжетную виртуальную реальность, а затем позволяют осуществлять погружение человеческого сознания в сложные виртуальные реальности.

Применение систем машинного интеллекта позволяет проводить аналогичный процесс для компьютерной техники. В частности, использование нейронных сетей и подобных им моделей в данной области позволило достигнуть существенных результатов. Однако это всего лишь частные случаи, возникает необходимость их соединения в целостную картину. Применение игровых технологий для решения данной проблемы оказывается оправданным, так как компьютерная игра объединяет множество программных составляющих. В итоге полученную методику образования на основе интеллектуальных игровых технологий отличают: системность, наличие множества уровней, взаимодействие в процессе игры, широкий простор для применения различных способов обучения. Ее преимуществами являются: интерактивность, быстрота получения результата, а также высокий уровень обеспечения эффективности.

Авторский подход подразумевает возможность осуществлять связанное обучение человека и машины. К тому же он позволяет изучать особенности естественного и искусственного интеллекта, создавать их гибридные формы. Появляется система «человек-игра-машина». В ее основе находится человеко-компьютерное взаи- 
модействие на уровне интеллекта и сознания. Взаимное обучение подобного рода несет в себе социальные и педагогические функции.

\section{Список литературы}

1. Гаврилова Т.И., Тимофеева Н.М. Исследование готовности школьников к проектированию развивающих компьютерных игр // Концепт. 2014. №6. С. 1-6.

2. Ляхов А.Ф., Тришин И.М. Компьютерное моделирование поведения игрока в интеллектуальной карточной игре с помощью нейронной сети // Компьютерные инструменты в образовании. 2013. №5. C. 54-64.

\section{References}

1. Gavrilova T.I., Timofeeva N.M. Issledovanie gotovnosti shkol'nikov k proektirovaniyu razvivayushhih komp'yuternyh igr [Study of the readiness of students for the design of developing computer games]. Koncept. 2014. №6, pp. 1-6.

2. Lyahov A.F., Trishin I.M. Komp'yuternoe modelirovanie povedeniya igroka v intellektual'noy kartochnoy igre s pomoshh'yu neyronnoy seti [Computer simulation of player behavior in an intellectual card game using a neural network]. Komp'yuternye instrumenty v obrazovanii, 2013, №5, pp. 54-64.

\section{ДАННЫЕ ОБ АВТОРЕ}

Гибадуллин Артур Амирзянович, аспирант

Нижневартовский государственный университет

ул. Ленина, 56, г. Нижневартовск, 628605, Российская Федераџия artur32pmi@yandex.ru

\section{DATA ABOUT THE AUTHOR}

Gibadullin Artur Amirzyanovich, graduate student

Nizhnevartovsk State University

56, Lenin Str., Nizhnevartovsk, 628605, Russian Federation

artur32pmi@yandex.ru

ORCID: 0000-0003-2545-9355 